pulmonary tuberculosis, although these constitute for the most part a late manifestation of the infection. Even then the investigation of the patient lacks reality and thoroughness. The idea of using the pronounced case of infection as a clue to the earlier-the conception of hunting down the infection in the households of the area with a view to its eradication-is overlooked or ignored. The opportunity of the dispensary as a field of fresh observation in many directions is entirely lost. With so limited an outlook the work tends to become routine.

Such procedure cannot be expected to lead us very far towards the final goal. As I ventured to say on a previous occasion :

"The calm repose of the physician who, stethoscope in hand, decides for or against a cavity in the lung, and then contents himself with prescribing cod-liver cil, and perhaps a chronic pectoral mixture, must be disturbed. His cerebration and locomotion both require stimulation, so that he may be led to anticipate the disease by earlier diagnosis, and to determine the potentialities of contagion in the home. With the infection detected he must leave no stone unturned in the study of the patient's life-history and environment, which may throw light on causation or maintenance of disease. Chiefly must the physician concern himself with the health of the rest of the household. The whole family-or as many members as possible-must be scrutinized with scientific suspicion.

"The patient will not be sent home merely rich in weighty counsels. He will be followed to his home by doctor and nurse with trained eye and skilled finger, prepared to observe and sift every fact and to hold a critical 'march past' of the household. That is the way to raid the haunts of the tubercle bacillus effectively."

\section{Searchlight Installation.}

Ernest Renan compared the human conscience to a lighthouse with recurrent flashes of illumination which guide the uncertain mariner on the sea of life. I like to think of the tuberculosis dispensary as a searchlight installation in the vast tubercle-tainted plantations of our communal life.

In proportion as the installation is complete and the operators are understanding, results will surely follow. The instrument suffuses with light the area of operations so that no facet of the problem remains in shadow. It superilluminates every case of tuberculosis and ensures a just appreciation of its character and bearings. The penetrating ray enters the home and, linking effect with cause, brings the means of healing and the assurance of prevention to each of the dwellers.

And, throughout the area thus illuminated, watchful observers "battling with custom, prejudice, and disease," may yet snatch further triumphs and gather new facts and ideas of which, to-day, we hardly dream.

\section{HYPOGLYCAEMIA DUE TO INSULIN IN CHILDREN.}

BY

\section{G. A. HARRISON, B.A., M.D.,*}

BIOCHEMIST, HOSPITAL FOR SICK CHILDREN, GREAT ORMOND STREET, LONDON.

Ir is not widely known that the level of blood sugar at which symptoms of hypoglycaemia occur is decidedly lower in children under 12 years of age than in adults. There is some variation in the level at which symptoms arise following insulin administration in adult diabetics. This is observed not only when comparing one patient with another, but also in repeated observations on the same patient. In my experience the level of blood sugar when hypoglycaemic reactions occur in the adult usually lies between 60 and $80 \mathrm{mg}$. per $100 \mathrm{c.cm}$., though very occasionally values as high as 100 and even 110 or $130 \mathrm{mg}$., or as low as $50 \mathrm{mg}$., have been encountered at the time of the reaction. Anomalous results (outside the range of 60 to $80 \mathrm{mg}$.) have been experienced too often now to be explicable solely on the basis of analytical errors. It is possible that the rate of fall of the blood sugar is of more consequence than the actual level in determining the onset of symptoms, though I have not uncommonly met with rapid falls (for example, from 328 to $53 \mathrm{mg}$. per $100 \mathrm{c.cm}$.

\footnotetext{
* Working on diabetes with a grant from the Medical Research Council.
}

in five hours) without resultant symptoms. Another possible explanation is that it is the concentration of sugar in the central nervous system that matters, and tho sugar content of the peripheral blood may be either above or below this critical value in certain circumstances.

In eleven diabetic children, aged 1 to 11 years, treated with insulin, twenty-eight analyses out of some hundreds showed a blood sugar of less than $50 \mathrm{mg}$. per $100 \mathrm{c.cm}$. without any concomitant clinical symptoms of hypoglycaemia. The lowest value was $28 \mathrm{mg}$., and the average of the twenty-eight analyses $39 \mathrm{mg}$. In three additional records (29, 44, and $45 \mathrm{mg}$. respectively) there were slight symptoms only. On thirty occasions in the above cases values between 50 and $59 \mathrm{mg}$. were found in the absence of symptoms. Typical examples follow. All analyses were made by Maclean's method, and in duplicate.

Case 1.-Male, aged 1 year and 2 months. Blood sugar on admission $442 \mathrm{mg}$. per $100 \mathrm{c.cm}$. On the third day of insulin treatment the blood sugar was $32 \mathrm{mg}$. four hours after the morning injection of 10 units, but there were no signs of hypoglycaemic reaction. Before the injection the blood sugar was $244 \mathrm{mg}$. The diet at this time consisted of $24 \mathrm{oz}$. of milk daily. On six subsequent occasions the blood sugar was reduced to values between 28 and $49 \mathrm{mg}$. per $100 \mathrm{c} . \mathrm{cm}$. some three to five hours after 6 units of insulin, without any signs of a reaction. On another occasion there were definite signs of hypoglycaemia. The baby was pale and slightly drowsy. He tended to fal forward, burying his head in the clothes. Blood analysis yielded the figure $44 \mathrm{mg}$. sugar per $100 \mathrm{c.cm}$. Five grams of carbohydrate (orange juice) restored the patient to normal.

The low levels of blood sugar are striking in this baby. As in adults, the level at which clinical signs occur is not a fixed point. On one day there were definite signs with a blood sugar of $44 \mathrm{mg}$., on another no signs of a reaction with a blood sugar of $32 \mathrm{mg}$.

Case 2.-Female, aged 2 years and 1 month. The daily diet contained 37 grams of carbohydrate, 31 grams of protein, and 50 grams of fat; 10 units of insulin were given daily. There were no signs of hypoglycaemic reaction on seven occasions on which the blood sugar varied from 32 to $49 \mathrm{mg}$. per $100 \mathrm{c.cm}$. There were slight but definite signs (pallor and extreme hunger) on one occasion when the blood sugar was $29 \mathrm{mg}$. per $100 \mathrm{c.cm}$.

Case 3. Male, aged 3 years and 3 months. The blood sugar was 46 and $49 \mathrm{mg}$. per $100 \mathrm{c.cm}$. respectively on two occasions when there were no signs of a reaction.

Case 4.-Female, aged 4. Blood sugar $38 \mathrm{mg}$. per $100 \mathrm{c.cm}$. unaccompanied by clinical symptoms.

Case 5.-Female, aged 6. No symptoms when the blood sugar was $49 \mathrm{mg}$. per 100 c.cm.

Case 6. - Female, aged 9. Slight symptoms with blood sugar of $45 \mathrm{mg}$. per 100 c.cm. Symptoms relieved by 5 grams of carbohydrate (orange).

Case 7 .-Male, aged 11. Fixed diet of 60 grams of carbohydrate, 70 grams of protein, and 140 grams of fat daily. He was given 8 units of insulin half an hour before breakfast, and 5 units a 8 units of insulin half an hour before breakfast, and 5 units quarter of an hour before tea. The blood sugar results are
shown in the following table. There were no signs or symptoms shown in the following table. There were no signs or symptoms
of hypoglycaemic reaction throughout. The boy walked to the of hypoglycaemic reaction throughout. The boy walked to the
laboratory from the ward, and "played about" in the intervals laboratory from the ward, and played about
between the collections of the samples of blood.

\begin{tabular}{|c|c|c|c|c|c|c|c|}
\hline \multirow{3}{*}{\multicolumn{2}{|c|}{ Date. }} & \multicolumn{6}{|c|}{ Blood Sugar, mg. per 100 c.cm. } \\
\hline & & \multicolumn{5}{|c|}{ Hours after Morning Dose of Insulin. } & \multirow{2}{*}{$\begin{array}{l}\text { 1: Hours } \\
\text { after } \\
\text { Evening } \\
\text { Dose. }\end{array}$} \\
\hline & & $1 \frac{1}{2}$ & $2 \frac{1}{2}$ & $3 \frac{1}{3}$ & 5 & 6 & \\
\hline $\begin{array}{c}1926 . \\
\text { April 19th }\end{array}$ & $\ldots$ & 63 & 60 & 55 & 137 & $12 j$ & - \\
\hline April 26th & $\ldots$ & - & 53 & - & 62 & - & 53 \\
\hline April 27th & $\ldots$ & - & 43 & - & 61 & - & 55 \\
\hline April 28th & $\ldots$ & - & 35 & - & 108 & - & - \\
\hline April 29th & $\ldots$ & \multicolumn{5}{|c|}{ Morning dose reduced to 5 units. } & \\
\hline May 3rd & $\ldots$ & - & 61 & - & 108 & - & 53 \\
\hline May 4th & $\ldots$ & - & 59 & - & - & 156 & - \\
\hline
\end{tabular}

It will be seen that in children the blood sugar may fall some 20 to $40 \mathrm{mg}$. below the " adult hypoglycaemic level" and yet be unaccompanied by signs of a reaction. It is well recognized that the general level of blood sugar in children is lower than that of adults, and therein may lie the explanation of these observations.

There is another point of practical importance. The hypoglycaemic reaction is not nearly so well defined in children as in adults. In the younger children and infants, 
of course, we are dependent solely on objective signs, and even the older children often are not able to describe their subjective symptoms as well as adults. In children the first signs of a hypoglycaemic reaction are often pallor, an unusual quietness, lassitude, and a tendency to doze whilst undisturbed; when examined, fretfulness and a greater tendency than usual to weep or cry are noted. None of these signs can be regarded as characteristic, for any or all of them may occur apart from hypoglycaemia. Sweating may or may not occur, but when it does it can hardly be regarded as a characteristic sign, sweating being not at all uncommon even in healthy children owing to excess of (bed) clothes, etc. Some writers consider that an increase in pulse rate is a valuable sign, but in my experience this is by no means constant and is not trustworthy.

\section{Treatment.}

The treatment of hypoglycaemia is well established-the administration of glucose or of other rapidly absorbed carbohydrates. The dose of carbohydrate depends on the degree of hypoglycaemia. In very mild attacks it is sometimes unnecessary even to give sugar. The patient may recover spontaneously or a cup of bovril or hot weak tea may suffice. In more severe but still mild reactions 5 grams of carbohydrate as orange juice $\left(45 \mathrm{c.cm}\right.$. or $\left.1 \frac{1}{2} \mathrm{oz}.\right)$ or as orange quarters (50 gm. or $1 \frac{3}{4} \mathrm{oz}$.), or as one lump of cane sugar dissolved in water and flavoured, if - desired, with lemon juice, are ample. If the symptoms have not obviously improved in fifteen to twenty minutes the 5 grams of carbohydrate should be repeated. Sometimes symptoms occur shortly before a meal is due; it is then often sufficient to give the meal or part of it a quarter or half an hour before the prescribed time, The exact details of treatment in any given case will- depend on circumstances-whether the patient is at home or under close observation in an institution, the availability of blood-sugar determinations, etc.-but it should bo an absolute rule to avoid treating hypoglycaemia with excessive amounts of carbohydrate and so rendering the patient hyperglycaemic. Of course, severe hypoglycaemic reactions demand larger doses of carbohydrate-for example, 15 grams as cane sugar (3 cubes); it may be necessary to give 15 to 20 grams of glucose by stomach tube, and this method can often be employed successfully even though the patient be semiconscious. Intravenous injection of glucose should be reserved for emergencies.

One practical point, sometimes forgotten, is that the sugar should invariably be administered in solution to ensure rapid absorption, and this is particularly important when hypoglycaemic symptoms are marked. One of my adult patients awakened one night with severe symptoms, and promptly swallowed with some difficulty two lumps of cane sugar. At the end of fifteen minutes the symptoms were worse, so she took some more lumps of sugar, and this was repeated till fifteen lumps in all had been devoured. The symptoms still persisted and she became very frightened. Fortunately she was then given some brandy and water, whereupon she came round in ten minutes. In the morning, of course, she was markedly hyperglycaemic (blood sugar $430 \mathrm{mg}$. per $100 \mathrm{c.cm}$.)

In children variation in the amount of exercise is a real difficulty, and not seldom accounts for hypoglycaemic reactions. Thus on several occasions I have been consulted by a parent who noted that her diabetic child had attacks of giddiness at the beginning of his holidays. The child played strenuous games in the garden in the holidays, whereas during term time he was seated at his lessons. Avoidance of severe exercise during the period two to five hours after insulin had been administered promptly caused the attacks of giddiness to cease. Adult diabetics soon learn to provide for unusually strenuous exercise by reducing slightly the dose of insulin, or by increasing the carbohydrate in the meal prior to the exercise; but it is much more difficult to make similar preparations in the case of children. The visit of a friend may result in a vigorous romp or in some quiet game; nobody can prophesy what will happen, least of all the child. The interference, unfortunate but absolutely necessary, with the spontaneous life of these little patients is one of the factors which make them so old for their years.

\section{AN AID TO THE RADIOGRAPHY OF THE MAXILLARY ANTRUM. \\ BY}

\author{
B. McKelvie, M.B., Ch.B.Vict.,
}

Clinical ASSISTANT, THROAT AND EAR DEPARTMENT, EDIXBURGH ROYAL INFIRMARY.

The following method is suggested as an aid to the diagnosis of cases of choanal polypus and new growth of the antrum, where an ordinary $x$-ray photograph often is of little use.

It can be ascertained in these cases whether a choonal polypus is coming from the antrum, and, if it is, whether

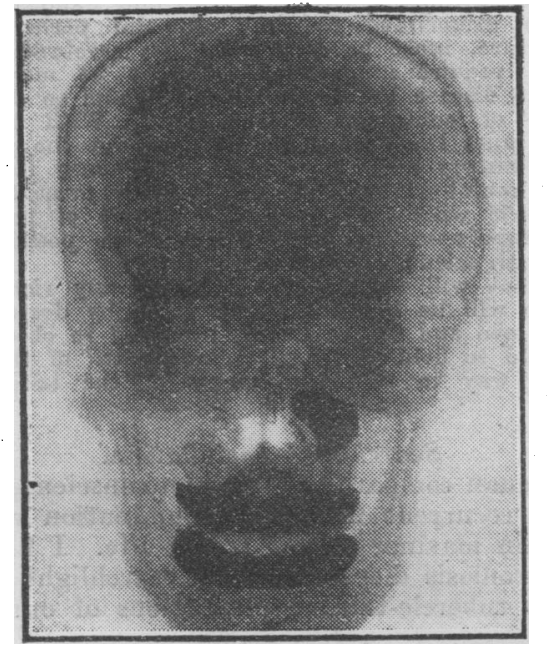

Fre. 1.-Skiagram of normal antrum injected with lipiodel.

it is attached in the usual situation or not. If new growth is suspected, the wall from which the growth is coming may often be decided.

Lipiodol (iodine in poppy-seed oil) is injected with the Watson-Williams syringe (the ordinary Lichtwitz cannula and a Record syringe may be used) into the antrum. Since lipiodol is opaque to $x$ rays, the less opaque growth or.

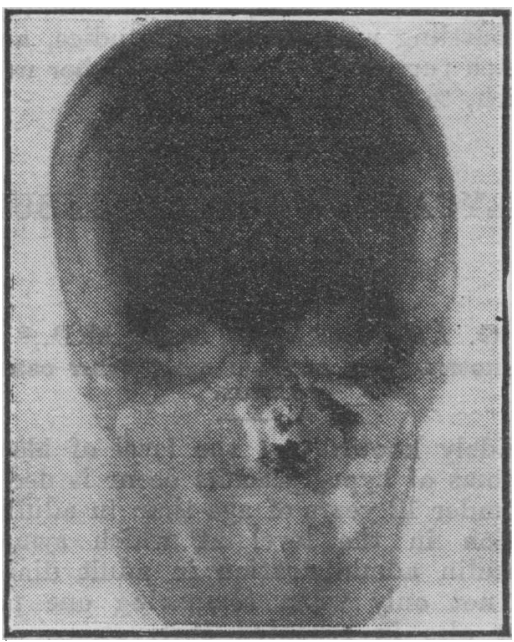

Fio. 2.-New growth of maxillary antrum. Lipiodol seen in outer part of antrum outlining the growth; wool seen in nose.

polypus is outlined by the dark shadow of the injected lipiodol. If a lateral and an antero-posterior view are taken a fairly accurate idea of the position and extent of the growth can be obtained. The method is excellent also for giving an outline of the sinus and showing the extent of alveolar recesses.

Puncture is made, after cocainization, through the inferior meatus of the nose, the middle meatus having previously been packed with wet wool extending as far back as possible in order to prevent the lipiodol from escaping by way of the normal and accessory ostia if these 